Применение углеродных нанотрубок для создания материалов поглощающих электромагнитное излучение и электродов суперконденсаторов

\begin{tabular}{lllll}
\hline \hline Александр В. Щегольков & ${ }^{1}$ & Energynano@yandex.ru & (D) 0000-0002-4317-0689 \\
Алексей В. Щегольков & 1 & alexxx5000@ mail.ru & (D) 0000-0002-1838-3842 \\
Фадей Ф. Комаров & 1 & komarovF@ bsu.by & (D) 0000-0001-8292-8942 \\
Иван Д. Парафимович & 2 & parfimovich@ bsu.by & (D) 0000-0002-5922-6333 \\
Олег О. Мильчанин & 2 & $\begin{array}{l}\text { milchanin@ bsu.by } \\
\text { Александр В. Кобелев }\end{array}{ }^{1}$ & kobelev77@ rambler.ru & (D) 0000-0002-1811-9988 \\
\hline
\end{tabular}

1 Тамбовский государственный технический университет ул. Советская, 106, г. Тамбов, 392000, Россия

2 Институт прикладных физических проблем имени А.Н. Севченко, ул. Курчатова 7, г. Минск, 220045, Беларусь

Аннотация. Углеродные нанотрубки являются эффективными наномодификаторами - обеспечивающими формирование разнообразных тепло и электрофизических свойств в композитных материалах. Функциональное назначение композитных материалов определяет тип и концентрацию углеродных наноструктур. Применение углеродных наноструктур в полимерных композитах, предназначенных для электромагнитного экранирования и электродных материалов суперконденсторов, является перспективным направлением в современном материаловедение. Методика изготовления радиопоглощающего композитного материалавключала пропитку пенополиуретановой заготовки - водной композитной суспензией, состоящей из воды, акрилового сополимера, включавшей углеродных нанотрубок «Таунит-МД». Структурные исследования образцов углеродных нанотрубок проводилось с использованием метода просвечивающей и сканирующей электронной микроскопии. Для этого ПЭМ и СЭМ исследования проводились с использованием электронного микроскопа HitachiH-800 с ускоряющим напряжением до 200 кэВ. Для проведения исследований из углеродных материалов были изготовлены электроды площадью $2 \mathrm{~cm}^{2}$. Активная масса готовилась из углеродного материала и связующего, поливинилендифторида. Представлены ПЭМ и СЭМ микрофотографии для образцов углеродных нанотрубок с коммерческим названием «Таунит-М». В этом случае углеродных нанотрубок характеризуются меньшими толщинами в диапазоне 10-20 нм с преимущественным средним размером - 12-15 нм. Структура трубок сильно дефектна. Толщина трубок меняется на отдельных участках (не превышающих сотен нм) более чем в 2 раза. Углеродных нанотрубки имеют неправильную форму - присутствуют отростки, изгибы. Анализ полученных результатов позволяет сделать вывод о том, что демонстрируемая пирамидальным РПМ характеристика отраженного ЭМИ сигнала близка по своим значениям аналогичной характеристике свободного пространства. При этом, по сравнению со свободным пространством, отмечается небольшое ослабление (3-4) дБ коэффициента отражения. Углеродных нанотрубки МД имеет характеристики, превышающие углеродную ткань «бусофит» по удельной массовой емкости, но уступающей ему по удельной поверхностной емкости. Кроме того это преимущество полностью исчезает при высоких плотностях тока, что может быть следствием закрытой макроструктуры и требует дальнейшей оптимизации технологии изготовления электродов

Ключевые слова: углеродные нанотрубки, полиуретан, наномодифицирование, суперконденсатор, электроды

\title{
The use of carbon nanotubes to create materials that absorb electromagnetic radiation and electrodes of supercapacitors
}

\begin{tabular}{|c|c|c|c|}
\hline Alexandr V. Shchegolkov & & Energynano@yandex.ru & (D) 0000-0002-4317-0689 \\
\hline Aleksei V. Shchegolkov & 1 & alexxx5000@mail.ru & (D) $0000-0002-1838-3842$ \\
\hline Fadey F. Komarov & & komarovF@bsu.by & (D) $0000-0001-8292-8942$ \\
\hline Ivan D. Parafimovich & 2 & parfimovich@bsu.by & (D) $0000-0002-5922-6333$ \\
\hline Oleg O. Milchanin & & milch & \\
\hline Alexander V. Kobelev & 1 & kobelev77@rambler.ru & (D) $0000-0002-1811-9988$ \\
\hline
\end{tabular}

1 Tambov State Technical University Sovetskaya street, 106, Tambov, 392000, Russia

2 Institute of Applied Physical Problems named after A.N. Sevchenko, st. Kurchatov 7, Minsk, 220045, Belarus

Для цитирования

Щегольков А.В., Щегольков А.В., Комаров Ф.Ф., Парафимович И.Д., Мильчанин О.О., Кобелев А.В. Применение углеродных нанотрубок для создания материалов поглощающих электромагнитное излучение и электродов суперконденсаторов // Вестник ВГУИТ. 2020. Т. 82. № 1. C. 267-272. doi:10.20914/2310-1202-2020-1-267-272

(C) 2020, Щегольков А.В. и др. / Shchegolkov A.V. et al.
For citation

Shchegolkov A.V., Shchegolkov A.V., Komarov F.F., Parafimovich I.D., Milchanin O.O., Kobelev A.V. The use of carbon nanotubes to create materials that absorb electromagnetic radiation and electrodes of supercapacitors. Vestnik VGUIT [Proceedings of VSUET]. 2020. vol. 82. no. 1. pp. 267-272. (in Russian). doi:10.20914/2310-1202-2020-1-267-272

This is an open access article distributed under the terms of the Creative Commons Attribution 4.0 International License 
Abstract. Carbon nanotubes are effective nanomodifiers - providing the formation of a variety of thermal and electrophysical properties in composite materials. The functional purpose of composite materials determines the type and concentration of carbon nanostructures. The use of carbon nanostructures in polymer composites intended for electromagnetic shielding and electrode materials of supercapacitors is a promising direction in modern materials science. The method of manufacturing a radio-absorbing composite material included impregnation of a polyurethane foam billet - an aqueous composite suspension consisting of water, an acrylic copolymer, and carbon nanotubes "Taunit-MD". Structural studies of carbon nanotube samples were performed using transmission and scanning electron microscopy. To do this, PAM and SAM studies were performed using a HitachiH-800 electron microscope with an accelerating voltage of up to $200 \mathrm{Kev}$. For research purposes, electrodes with an area of $2 \mathrm{~cm} 2$ were made from carbon materials. Active mass was prepared from a carbon material and a binder, polivinildenftorid. Show PEM and SAM micrographs for samples of carbon nanotubes with the commercial name "Taunit-M". In this case, carbon nanotubes are characterized by smaller thicknesses in the range of 10-20 nm with a preferred average size of 12-15 nm. The structure of the tubes is very defective. The thickness of the tubes varies in some areas (not exceeding hundreds of $\mathrm{nm}$ ) by more than 2 times. Carbon nanotubes have an irregular shape-there are processes, bends. The analysis of the obtained results allows us to conclude that the characteristic of the reflected EMI signal demonstrated by the pyramidal RPM is close in its values to that of the free space. At the same time, in comparison with the free space, there is a slight weakening (3-4) dB of the reflection coefficient. Carbon nanotubes MD has characteristics that exceed the carbon fabric "busofit" in terms of specific mass capacity, but inferior to it in terms of specific surface capacity. In addition, this advantage completely disappears at high current densities, which may be the result of a closed macrostructure and requires further optimization of the electrode manufacturing technology

Keywords: carbon nanotubes, polyurethane, nanomodification, supercapacitor, electrodes

\section{Введение}

Углеродные нанотрубки являются эффективными наномодификаторами - обеспечивающими формирование разнообразных тепло и электрофизических свойств в композитных материалах. Функциональное назначение композитных материалов определяет тип и концентрацию углеродных наноструктур. Применение углеродных наноструктур в полимерных композитах, предназначенных для электромагнитного экранирования и электродных материалов суперконденсторов, является перспективным направлением в современном материаловедение.

Рассматривая применение углеродных нанотрубок в рамках создания поглощающих электромагнитное излучение материалах следует учитывать, что наиболее эффективными для экранирования при известной частоте являются частицы наполнителя размером от $\lambda / 4$ до $\lambda / 2$, где $\lambda$-длина волны поглощаемого излучения. Также следует учитывать влияние толщины материала. В работе [1] показано, что эффективными радиопоглощающими свойствами при прочих равных условиях будет обладать материал толщиной $-\lambda / 20$ [2].

Радиопоглощающие покрытия пирамидального (РПП) типа широко используются на практике при построении высококачественных широкополосных безэховых камер [3]. В качестве радиопоглощающих материалов в составе таких покрытий используются: пенополиуретан, вспененный полистирол, полимерные пленки с металлическим покрытием и т. д. Наиболее технологичным в производстве и эксплуатации является пенополиуретан. Поглощение электромагнитного излученияв материале обеспечивается углеродосодержащей пропиткой.

Для изготовления образца пирамидального РПМ необходимо выполнить следующие этапы: определение геометрических параметров радиопоглощающего композита, выбор типа и концентрации наполнителя для обеспечения необходимого уровня при однократном отражении.

Расчет количества переотражений осуществляется по следующему приближенному методу (рисунок 1) [4]. Расчет ведется для луча, испытавшего минимальное количество переотражений в полостях РПМ. Это луч, точка первого отражения которого лежит в плоскости вершин пирамид:

$$
h_{2}=2\left(H-h_{1}\right) \operatorname{tg} \frac{\alpha}{2} /\left(\operatorname{tg} \theta_{1}+\operatorname{tg} \frac{\alpha}{2}\right) .
$$

Дальнейшее вертикальное перемещение луча в полости РПМ описывается:

$$
h_{n}=2\left(H-\sum_{i=1}^{n} h_{i 1}\right) \operatorname{tg} \frac{\alpha}{2} /\left(\operatorname{tg} \theta_{n-1}+\operatorname{tg} \frac{\alpha}{2}\right)
$$

где,

$$
\theta_{n-1}=\alpha(n-1)+\theta \text {. }
$$

Условие выхода луча из поглощающей полости и определение количества переотражений N:

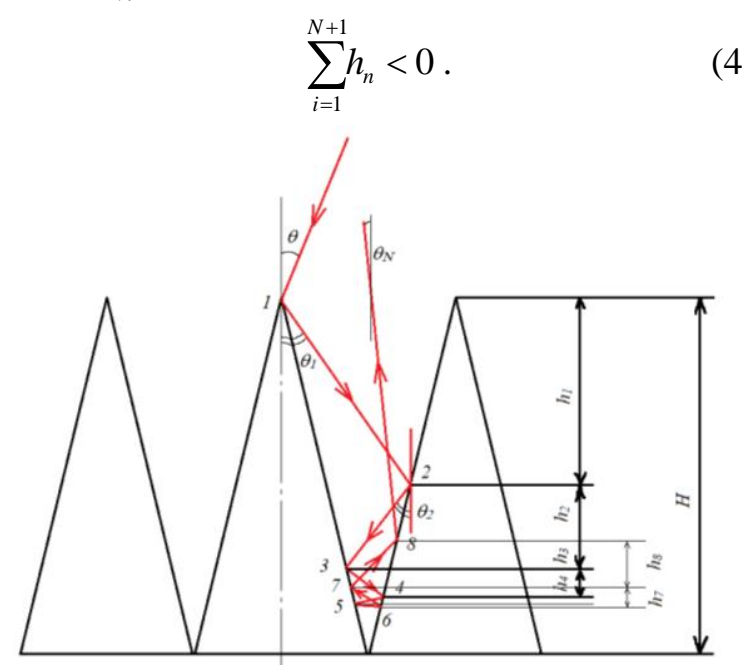

Рисунок 1. Расчет переотражений в полости пирамидальных РПМ рассеивающего типа

Figure 1. Calculation of re-reflections in the cavity of pyramidal RPMS of the scattering type 
Углеродные структуры и нанотрубкипридавая материалу функциональные свойства, также могут способствовать улучшению конструкционных характеристик, а именно механической прочности [5], стойкости к эрозионному износу [6] и повышению электропроводности [7, 8].

Для получения эффективных электродных материалов суперконденсаторов -активно используется комбинирование активированных углей с углеродными нанотрубками. В работе [9] приведены результаты исследований активированного углерода и углеродных нанотрубок в водных растворах различных солей, серной кислоте и щелочи. Авторы проходят к выводу об определяющей роли удельной поверхностии электропроводности электролита в достижении высоких значений удельной емкости. Наибольшую электропроводность имеют щелочные электролиты. При плотности тока 1-2 A/г материал с удельной поверхностью $2400 \mathrm{~m}^{2} / \Gamma$ в солевых, кислых и щелочном электролитах обладает емкостью 150-250 Ф/г, причем нижний предел относится к щелочным электролитам, верхний - к сульфиту натрия.

Двойнослойный суперконденсатор с электродами на основе углеродных нанотрубок в сернокислом электролите обеспечивает удельную емкость 115 Ф/г [10].

Целью настоящей работы состоит в применение углеродных нанотрубок для модификации композиционных материалов с радиопоглощающими свойствами и электродных материалов суперконденсаторов.

\section{Материалы и методы}

Радиопоглощающий материал формировался путем пропитки пенополиуретановой заготовки водной композитной суспензией, состоящей из воды, акрилового сополимера, включавшей углеродных нанотрубок «Таунит-МД». Компоненты диспергировались при помощи ультразвукового гомогенизаторaUP400St в течение 30 мин, при температуре, не превышающей $60{ }^{\circ} \mathrm{C}$. Мощность ультразвука в течение всего процесса диспергирования постепенно повышалась до 80 Вт.

Исследование процессов взаимодействия электромагнитного излучения с радиопоглощающими материалами проводилось в диапазоне от 300 МГц до 40 ГГц с использованием векторного анализатора цепей N5290AKeysightTechnologies (США).

Структурные исследования образцов нанотрубок проводилось с использованием метода просвечивающей и сканирующей электронной микроскопии. Для этого ПЭМ и СЭМ исследования проводились с использованием электронного микроскопа HitachiH-800 с ускоряющим напряжением до 200 кэВ.
Для проведения исследований из углеродных материалов были изготовлены электроды площадью $2 \mathrm{~cm}^{2}$. Активная масса готовилась из углеродного материала и связующего, поливинилендифторида. Связующее вводили в электродную массу в виде $2 \%$ раствора, полученную суспензию подвергали ультразвуковой обработке в течение 20 мин, после чего наносили на коллектор тока и высушивали при температуре $100{ }^{\circ} \mathrm{C}$ в течение 40 мин.

В качестве электролита использовали раствор гидроксида натрия концентрации 2 моль/л.

Для исследования характеристик материалов применяли метод гальваностатического циклирования.

Для гальваностатических условий удельную (по массе активного материала) емкость, $C_{m l}, \Phi / г$, рассчитывали как:

$$
C_{m I}=\frac{I \cdot t_{p}}{\Delta E \cdot m},
$$

где $I$ - задаваемый ток разряда, $t_{p}$ - время разряда, $\Delta E$ - диапазон потенциалов разрядной кривой, $m$ - масса активного материала.

Удельную емкость (на единицу поверхности), $C_{S I}, \Phi / \mathrm{cm}^{2}$ рассчитывали по аналогичной формуле:

$$
C_{S I}=\frac{I \cdot t_{p}}{\Delta E \cdot S} .
$$

Исследования проводили для УНТ-МД и углеродная ткань «бусофит».

\section{Результаты}

На рисунке 2 представлены ПЭМ микрофотографии для образцов МУНТ «Таунит-М» и «Таунит-МД». Из рисунка 2 следует, что МУНТ характеризуются меньшими толщинами в диапазоне 10-20 нм с преимущественным средним размером - от 12 до 15 нм. Структура трубок сильно дефектна. Толщина трубок меняется на отдельных участках (не превышающих сотен нм) более чем в 2 раза. Многие МУНТ имеют неправильную форму - присутствуют отростки, изгибы. В клубках трубок регистрируются и крупные частицы загрязнений (размерами до сотен нм) Переплетения нанотрубок в материале «Таунит-М» гораздо выше, чем наблюдалось для материала «Таунит». Однако в целом, структура массива углеродных нанотрубок схожа с материалом «Таунит».

На рисунке 3 представлены результаты исследования пирамидального РПМ на основе пенистого полиуретана, акрилового сополимера и МУНТ «Таунит-МД» с массовой концентрацией 5 вес.\%. 

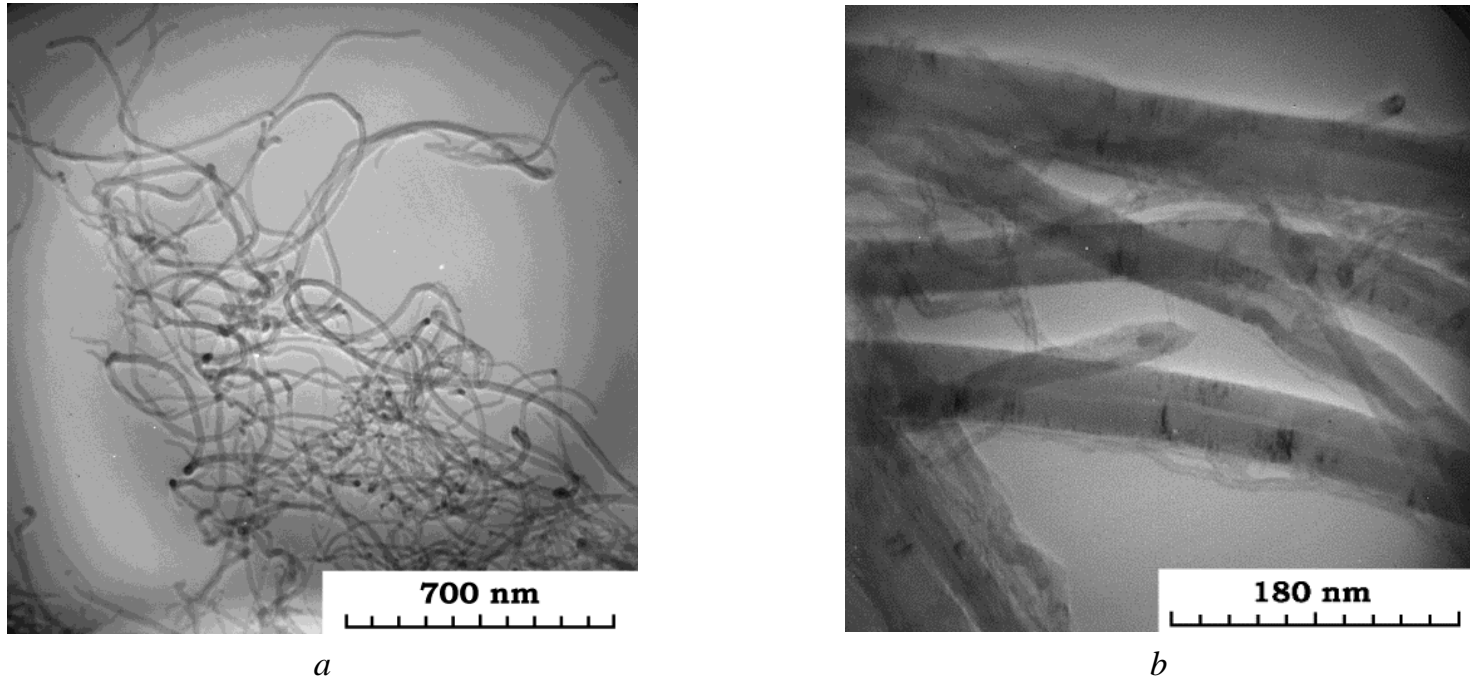

Рисунок 2. ПЭМ микрофотографии МУНТ: $a$ - «Таунит-М»; $b$ - «Таунит-МД»

Figure2. TEM micrographs of MWNTs: $a$ - "Taunit-M"; $b$ - "Townit-MD"

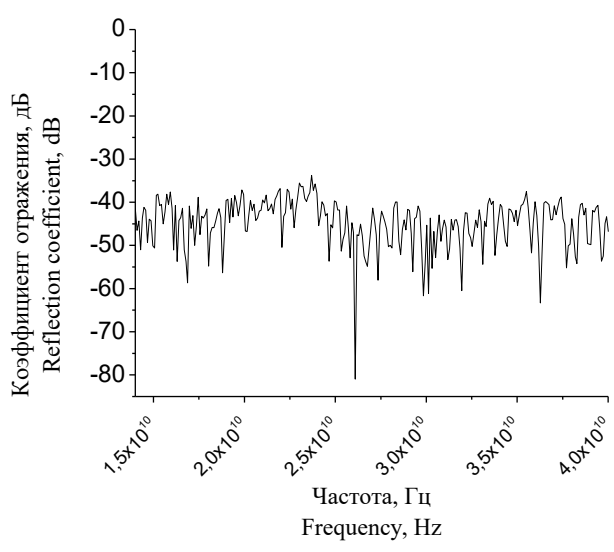

$a$

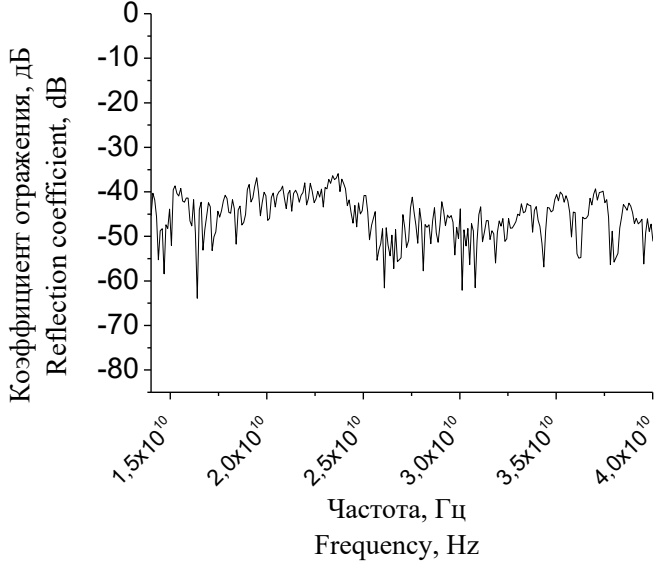

$b$

Рисунок 3. Частотная зависимость коэффициента отражения электромагнитного излучения для: $a-$ свободного пространства; $b$ - пирамидального радиопоглощающего материала

Figure3. Frequency dependence of the reflection coefficient of electromagnetic radiation for: $a-$ free space; $b-$ pyramidal radio-absorbing material

В таблице 1 представлены характеристики исследованных материалов при гальваностатическом циклировании.

Таблица 1 .

Характеристики исследованных материалов при гальваностатическом циклировании

Table 1.

Characteristics of the studied materials during galvanostatic Cycling

\begin{tabular}{|c|c|c|c|c|}
\hline \multirow{2}{*}{$\begin{array}{c}\text { Электродный } \\
\text { материал }\end{array}$} & \multicolumn{4}{|c|}{$\begin{array}{c}\text { Удельная емкость при } \\
\text { плотности тока, мА/см }\end{array}$} \\
$\begin{array}{c}\text { Electrode } \\
\text { material }\end{array}$ & \multicolumn{4}{|c|}{ density, mA/cm } \\
\cline { 2 - 5 } & \multicolumn{3}{|c|}{2} & \multicolumn{2}{|c|}{5} \\
\cline { 2 - 5 } & $\begin{array}{c}\Phi / \Gamma \\
\mathrm{F} / \mathrm{g}\end{array}$ & $\begin{array}{c}\Phi / \mathrm{cm}^{2} \\
\mathrm{~F} / \mathrm{cm}^{2}\end{array}$ & $\begin{array}{c}\Phi / \Gamma \\
\mathrm{F} / \mathrm{g}\end{array}$ & $\begin{array}{c}\Phi / \mathrm{cm}^{2} \\
\mathrm{~F} / \mathrm{cm}^{2}\end{array}$ \\
\hline Бусофит Busofit & 16,4 & 0,41 & 19 & 0,35 \\
\hline $\begin{array}{c}\text { УНT-MД UNT- } \\
\text { MD }\end{array}$ & 32 & 0,16 & 22 & 0,11 \\
\hline
\end{tabular}

\section{Обсуждение}

Анализ представленных на рисунке 3 результатов исследований позволяет сделать вывод о том, что демонстрируемая пирамидальным РПМ характеристика отраженного ЭМИ сигнала близка по своим значениям аналогичной характеристике свободного пространства. При этом, по сравнению со свободным пространством, отмечается небольшое ослабление (3-4) дБ коэффициента отражения.

Таким образом, на основе сформированного в работе материала могут быть изготовлены элементы безэховой камера с рабочим диапазоном от 2 до 40 ГГц. УНТ-МД имеет характеристики, превышающие углеродную ткань «бусофит» по удельной массовой емкости, но уступающей ему по удельной поверхностной емкости. 
Кроме того, это преимущество полностью исчезает при высоких плотностях тока, что может быть следствием закрытой макроструктуры и требует дальнейшей оптимизации технологии изготовления электродов (таблица 1).

\section{Заключение}

Применение углеродных нанотрубок позволяет получить, как радиопоглащающие материалы, так и электродные материалы для суперконденсаторов. В случае применения углеродных нанотрубок для электродов суперконденсаторов - им отводится роль вспомогательных материалов - способных улучшить электропроводность и улучшение емкости. Применение углеродной ткани «бусофит» и углеродных нанотрубок, как комбинированного материала, может позволить улучшить электрофизические свойства и расширить диапазон эффективной работы.

\section{Благодарности}

Исследование выполнено при финансовой поддержке РФФИ в рамках научного проекта № 18-53-00032 Бел_а.

\section{Литература}

1 Уфимцев П.Я. Метод краевых волн в физической теории дифракции. М.: Советское радио, 1962. 243 с.

2 Розанов Н. Фундаментальное ограничение для ширины рабочего диапазона радиопоглощающих покрытий // Радиотехника и электроника. 1999. Т. 44. № 5. С. 526-530.

3 Мицмахер М.Ю., Торганов В.А. Безэховые камеры СВЧ. Москва: Радио и связь, 1982. 128 с.

4 Будай А.Г., Кныш В.П., Алешкевич Н.Н., Громыко А.В. и др. Структурная оптимизация радиопоглощающих покрытий пирамидального типа // Прикладные проблемы оптики, информатики, радиофизики и физики конденсированного состояния: материалы международной научно-практической конференции. Минск: НИИ ПФП имени А.Н. Севченко, 2013. С. 130-132.

5 Chen J., Hutchings I.M., Deng T., Bradley M.S. et al. The effect of carbon nanotube orientation on erosive wear resistance of CNT-epoxy based composites // Carbon. 2014. V. 73. P. 421-431. doi: 10.1016/j.carbon.2014.02.083

6 Al-Saleh M.H., Al-Anid H.K., Hussain Y.A. CNT/ABS nanocomposites by solution processing: Proper dispersion and selective localization for low percolation threshold // Composites Part A: Applied Science and Manufacturing. 2013. V. 46. P. 53-59. doi: 10.1016/j.compositesa.2012.10.010

7 Bauhofer W., Kovacs J.Z. A review and analysis of electrical percolation in carbon nanotube polymer composites // Composites Science and Technology. 2009. V. 69. №. 10. P. 1486-1498. doi: 10.1016/j.compscitech.2008.06.018

8 Bychanok D., Gorokhov G., Meisak D., Plyushch A. et al. Exploring Carbon Nanotubes/BaTiO3/Fe3O4 Nanocomposites as Microwave Absorbers // Progress In Electromagnetics Research C. 2016. V. 66. P. 77-85. doi: 10.1109/ICEAA.2015.7297071

9 Lota K., Sierczynska A., Acznik I. Effect of aqueous electrolytes on electrochemical capacitor capacitance // Chemik. 2013. V. 67. № 11. P. 1138-1145.

10 Chen J.H., Li W.Z., Wang D.Z., Yang S.X. et al. Electrochemical characterization of carbon nanotubes as electrode in electrochemical double-layer capacitors // Carbon. 2002. V. 40. № 8. P. 1193-1197.

\section{References}

1 Ufimtsev P.Ya. The method of boundary waves in the physical theory of diffraction. Moscow, Sovetskoye radio, 1962. 243 p. (in Russian).

2 Rozanov N. Fundamental restriction for the width of the working range of radar absorbing coatings. Radio engineering and electronics. 1999. vol. 44. no. 5. pp. 526-530. (in Russian).

3 Mitsmakher M.Yu., Torganov V.A. Microwave anechoic chambers. Moscow, Radio i svyaz', 1982.128 p. (in Russian).

4 Buday A.G., Knysh V.P., Aleshkevich N.N., Gromyko A.V. et al. Structural Optimization of Pyramidal Type Radar Absorbing Coatings. Applied Problems of Optics, Computer Science, Radiophysics and Condensed Matter Physics: Materials of the International Scientific and Practical Conference. Minsk, NII PFP named after A.N. Sevchenko, 2013. pp. 130-132. (in Russian).

5 Chen J., Hutchings I.M., Deng T., Bradley M.S. et al. The effect of carbon nanotube orientation on erosive wear resistance of CNT-epoxy based composites. Carbon. 2014. vol. 73. pp. 421-431. doi: 10.1016/j.carbon.2014.02.083

6 Al-Saleh M.H., Al-Anid H.K., Hussain Y.A. CNT/ABS nanocomposites by solution processing: Proper dispersion and selective localization for low percolation threshold. Composites Part A: Applied Science and Manufacturing. 2013. vol. 46. pp. 53-59. doi: 10.1016/j.compositesa.2012.10.010

7 Bauhofer W., Kovacs J.Z. A review and analysis of electrical percolation in carbon nanotube polymer composites. Composites Science and Technology. 2009. vol. 69. no. 10. pp. 1486-1498. doi: 10.1016/j.compscitech.2008.06.018

8 Bychanok D., Gorokhov G., Meisak D., Plyushch A. et al. Exploring Carbon Nanotubes/BaTiO3/Fe3O4 Nanocomposites as Microwave Absorbers. Progress In Electromagnetics Research C. 2016. vol. 66. pp. 77-85. doi: 10.1109/ICEAA.2015.7297071

9 Lota K., Sierczynska A., Acznik I. Effect of aqueous electrolytes on electrochemical capacitor capacitance. Chemik. 2013. vol. 67. no. 11. pp. 1138-1145.

10 Chen J.H., Li W.Z., Wang D.Z., Yang S.X. et al. Electrochemical characterization of carbon nanotubes as electrode in electrochemical double-layer capacitors. Carbon. 2002. vol. 40. no. 8. pp. 1193-1197. 


\section{Сведения об авторах}

Александр В. Щегольков к.т.н., доцент, кафедра техники и технологий производства нанопродуктов, Тамбовский государственный технический университет, ул. Советская, 106, г. Тамбов, 392000, Россия, Energynano@yandex.ru (Dhttps://orcid.org/0000-0002-4317-0689

Алексей В. Щегольков аспирант, кафедра техники и технологий производства нанопродуктов, Тамбовский государственный технический университет, ул. Советская, 106, г. Тамбов, 392000, Россия, alexxx5000@mail.ru

(Dhttps://orcid.org/0000-0002-1838-3842

Фадей Ф. Комаров д.ф-м.н., профессор, лаборатория элионики, Институт прикладных физических проблем им. А.Н. Севченко, Курчатова, 7, г. Минск, 220045, Беларусь, komarovF@bsu.by

Dhttps://orcid.org/0000-0001-8292-8942

Иван Д. Парафимович младший научный сотрудник, лаборатория элионики, Институт прикладных физических проблем им. А.Н. Севченко, Курчатова, 7, г. Минск, 220045, Беларусь, parfimovich@bsu.by

(1Dhttps://orcid.org/0000-0002-5922-6333

Олег О. Мильчанин к.ф-м.н, старший научный сотрудник, лаборатория элионики, Институт прикладных физических проблем им. А.Н. Севченко, Курчатова, 7, г. Минск, 220045, Беларусь, milchanin@ bsu.by

Александр В. Кобелев к.т.н., доцент, кафедра электроэнергетики, Тамбовский государственный технический университет, ул. Советская, 106, г. Тамбов, 392000, Россия, kobelev77@ rambler.ru Ohttps://orcid.org/0000-0002-1811-9988

\section{Вклад авторов}

Bсе авторы в равной степени принимали участие в написании рукописи и несут ответственность за плагиат

\section{Конфликт интересов}

Авторы заявляют об отсутствии конфликта интересов.

\section{Information about authors}

Alexandr V. Shchegolkov Cand. Sci. (Engin.), associate professor, technique and production technology of nanoproducts department, Tambov State Technical University, Technical University, Sovetskaya str., 106, Russia, Energynano@yandex.ru (Dhttps://orcid.org/0000-0002-4317-0689

Aleksei V. Shchegolkov graduate student, technique and production technology of nanoproducts department, Tambov State Technical University, Tambov State Technical University, alexxx5000@mail.ru

(Dhttps://orcid.org/0000-0002-1838-3842

Fadey F. Komarov Dr. Sci. (Phys.-Math.), professor, laboratoty of elioniks, Institute of Applied Physical Problems, Kurchatova Av., 7, 220045, Belarus, komarovF@ bsu.by

(Dhttps://orcid.org/0000-0001-8292-8942

Ivan D. Parafimovich junior researcher, laboratoty of elioniks, Institute of Applied Physical Problems, Kurchatova Av., 7, 220045, Belarus, parfimovich@bsu.by (D)https://orcid.org/0000-0002-5922-6333

Oleg O. Milchanin Cand. Sci. (Phys.-Math.), senior researcher, laboratoty of elioniks, Institute of Applied Physical Problems, Kurchatova Av., 7, 220045, Belarus, milchanin@bsu.by

Alexander V. Kobelev Cand. Sci. (Engin.), associate professor, electric power department, Tambov State Technical University, Sovetskaya str., 106, Russia,kobelev77@ rambler.ru Dhttps://orcid.org/0000-0002-1811-9988

\section{Contribution}

All authors are equally involved in the writing of the manuscript and are responsible for plagiarism

\section{Conflict of interest}

The authors declare no conflict of interest.

\begin{tabular}{ccc}
\hline Поступила 10/02/2020 & После редакции 21/02/2020 & Принята в печать 02/03/2020 \\
\hline Received $10 / 02 / 2020$ & Accepted in revised 21/02/2020 & Accepted 02/03/2020 \\
\hline
\end{tabular}

